\title{
Growth factors in the initial stage of bone formation, analysis of their expression in chondrocytes from epiphyseal cartilage of rat costochondral junction
}

\author{
Anna Hyc, Stanislaw Moskalewski, Anna Osiecka-Iwan
}

Department of Histology and Embryology, Medical University of Warsaw, Warsaw, Poland

\begin{abstract}
Introduction. In endochondral ossification septoclasts and osteoclasts (also called chondroclasts) release growth factors deposited in non-calcified and calcified zones of the growth plate. They stimulate, within the metaphysis, initial stages of the bone formation. We have recently reported quantitation of several growth factors in calcified cartilage from calf costochondral junction. Data from the analogous human cartilage could possibly help to choose efficient combinations of growth factors for clinical applications, but the amount of the calcified cartilage needed for analysis of numerous growth factors would be difficult to collect. The estimation of growth factors expression in endochondral chondrocytes may, indirectly, indicate which of them play a leading role in the stimulation of osteoprogenitor cells in metaphysis. To test this hypothesis, we used rat chondrocytes to evaluate mRNA levels of several growth factors. Materials and methods. Chondrocytes were isolated from proliferative and hypertrophic zones of the epiphyseal cartilage forming costochondral junctions of inbred Lewis rats. The total RNA was isolated from chondrocytes and the level of mRNA for bone morphogenetic proteins 1-7 (BMP-1-7), vascular endothelial growth factor A (VEGF-A), basic fibroblast growth factor (bFGF), growth/differentiation factor 5 (GDF-5), NEL-like protein 1 (NELL-1), transforming growth factor beta 1 (TGF- $\beta 1$ ), mesencephalic astrocyte-derived neurotrophic factor (MANF), connective tissue growth factor (CTGF), osteoclast-stimulating factor 1 (OSTF-1) and insulin-like growth factor 1 (IGF-1) was evaluated using real-time PCR method.

Results. All studied factors were expressed. The highest level of mRNA was detected for CTGF, MANF, VEGF-A and TGF- $\beta 1$. Expression was also quite high for BMP-1, BMP-2, BMP-5, BMP-6, BMP-7, IGF-1, GDF-5 and OSTF-1. Very low level of mRNA was detected for BMP-3, BMP-4 and NELL-1.

Conclusions. Chondrocytes from the proliferative and hypertrophic zones of the growth plate produce factors involved in the cartilage metabolism and bone formation. The determination of these growth factors in humans could help to choose their optimal composition necessary for stimulation of bone formation in clinical practice. In rat the best stimulation of bone formation would presumably be achieved with a mixture of BMP-2, BMP-5, BMP-6 and BMP-7. (Folia Histochemica et Cytobiologica 2021, Vol. 59, No. 3, 178-186)
\end{abstract}

Key words: rat; epiphyseal cartilage; costochondral junction; bone formation; growth factors; qPCR

\section{Introduction}

Epiphyseal growth plate composed of hyaline cartilage constitutes the dynamic structure with stem cells

\footnotetext{
Correspondence address: Anna Osiecka-Iwan Ph.D.

Department of Histology and Embryology,

Medical University of Warsaw,

Chalubinskiego 5, PL-02004 Warsaw, Poland

phone/fax: +48 2262952 82, e-mail: aiwan@wum.edu.pl
}

present in the reserve zone which differentiate and rapidly divide in the proliferative zone, enlarge in the hypertrophic zone, and finally undergo apoptosis in the provisional calcification zone close to the metaphysis [1-8]. Calcification of the growth cartilage begins in the extracellular matrix (ECM) forming longitudinal septa and separating rows of chondrocytes. In the hypertrophic zone septa, roundish bodies appear that are produced by chondrocytes and called matrix vesicles. They serve as initiation sites of mineral dep-

This article is available in open access under Creative Common Attribution-Non-Commercial-No Derivatives 4.0 International (CC BY-NC-ND 4.0) license, allowing to download articles and share them with others as long as they credit the authors and the publisher, but without permission to change them in any way or use them commercially. (C) Polish Society for Histochemistry and Cytochemistry 
osition in the cartilage [9-11]. Calcified matrix vesicles join into larger structures, called globular units and finally into massive calcium phosphate deposits occupying most of the calcification zone territory [12].

The proliferation and differentiation of chondrocytes in the epiphyseal cartilage are regulated by numerous factors belonging to the TGF- $\beta$ superfamily. In the immunocytochemical studies bone morphogenetic proteins 1-7 (BMPs 1-7) were demonstrated in proliferative, maturing and late hypertrophic chondrocytes of rat tibial growth plate [13]. BMPs 1-7 and vascular endothelial growth factor (VEGF) were also found in matrix vesicles isolated from rat growth plate, which could carry them from chondrocytes into the matrix [14]. BMP signalling is required for maintenance of the differentiated phenotype, control of cell proliferation, expression of hypertrophic phenotype of chondrocytes $[15,16]$ and skeletal development [17]. BMP-2 and BMP-6 are upregulated in hypertrophic zone compared with resting zone and proliferative zone from rat growth plate while signalling inhibitor BMP-3 is highly expressed in resting zone [18]. In turn, BMP-5 upregulated expression of hypertrophic zone markers - parathyroid receptor 1 and collagen type X alpha 1 in cell line ATDC5 serving as the growth plate model [19].

Vascular invasion into growth plate depends on the production of VEGF by hypertrophic chondrocytes [20] with invading endothelial cells as a target [21]. Moreover, VEGF acts also as a survival factor for growth plate chondrocytes [21], is instrumental for invasion of osteoclasts into the hypertrophic cartilage $[22,23]$, and serves as the mediator connecting angiogenesis with osteogenesis [24].

Gradients of BMPs across the growth plate form many local signaling pathways and may be a key mechanism responsible for spatial regulation of chondrocyte proliferation and differentiation. Due to cross-talks and feedback mechanisms, these interwoven pathways display a network-like structure. This network is able to capture the different states (resting, proliferating and hypertrophic) that chondrocytes go through as they progress within the growth plate and finally support vascular invasion $[1,8,25,26]$.

Both in our previous work [27] and in the present contribution, an advantage was taken of the similarity in the structure and function of epiphyseal growth plate and costochondral junctions [28-30]. It was possible to obtain sufficient amount of calcified cartilage from the zone of provisional calcification in costochondral junctions of calf ribs for quantitative determination by ELISA of deposited growth factors. It had high content of growth/differentiation factor 5 (GDF-5),BMP-7, and NEL-like protein 1(NELL-1) [27] suggesting that these factors play a leading role in the stimulation of bone formation within calf epiphyseal cartilage. Other factors, such as BMP-2, BMP-3. BMP-4; basic fibroblast growth factor (bFGF), VEGF and transforming growth factor beta 1 (TGF- $\beta 1$ ) occurred in lower quantities. Still others, BMP-1, BMP-5, BMP-6, insulin-like growth factor 1 (IGF-1), osteoclast-stimulating factor 1 (OSTF-1), mesencephalic astrocyte-derived neurotrophic factor (MANF) and connective tissue growth factor (CTGF) were not detected. Thus, it appears that epiphyseal chondrocytes not only produce growth factors as the regulators of their own growth and differentiation but also prepare considerable store of chosen factors for the initial period of bone deposition.

The initial enthusiasm for the use of bone morphogenetic factors in the clinical practice $[31,32]$ subsided due to the observations of unfavourable side effects such as postoperative inflammation, ectopic bone formation, osteoclast-mediated severe bone resorption and life-threatening cervical spine swelling $[33,34]$ as well as by apprehension of neoplastic growth stimulation [35]. There are also problems with the choice of proper carrier vehicle for BMPs. Sodium acetate buffer, bovine type I collagen matrix in combination with carboxymethyl-cellulose, absorbable collagen sponge, polymers or ceramic composites were tested.

Alternative BMP delivery systems include also viral vectors or genetically altered cells [36]. An absorbable collagen sponge as a carrier for BMP-2 has been approved by U.S. Food and Drug Administration (FDA) for the use in humans, but the optimal carrier vehicle for BMP-2 or other growth factors delivery has yet not been established [33]. Recently, gene delivery is a new option for achieving the sustained release of BMP-2 and stimulation of bone defects healing. It involves transferring a target gene encoding BMP-2 into the defect site using vectors carrying the gene. Then, the cells transfected by vectors carrying the gene produce the target molecules in vivo and secrete the target molecules into the defect site. The drug release period can be controlled by the vector carrying the gene $[37,38]$.

Another approach for the improvement of BMPs administration results involved construction of injectable bmp-2 delivery system based on collagen derived microspheres and alginate. This system, when tested in rats, considerably reduced BMP-2 dose needed for successful induction of ectopic bone formation in rats [39]. As a delivery system for BMP-2 a non-polymer hydrogel, based on the self-assembly of small amphiphilic glycosyl-nucleolipids into micellar structures was also tried. When tested in mice it stimulated ectopic bone formation at low doses of BMP-2 [40].

The formation of bone within growth plate is dependent on several growth factors which presumably 
act synergistically and thus may be effective at low concentrations to allow harmonious osteogenesis. We have recently shown that in the bovine epiphyseal cartilage BMP-7, NELL-1 and GDF-5 may play a key role in early mineralization [27]. The question arises which other growth factors and at what concentration are deposited in calcified cartilage from human growth plate. In view of the similarity between the mechanisms of endochondral bone formation during development and healing of mature bone fractures [41] it is plausible that recognition of growth factors deposited in human calcified cartilage could help to choose optimal composition of growth factors for the stimulation of bone formation in clinical practice. Unfortunately, the amount of calcified human cartilage from growth plates needed for analysis of numerous growth factors would be difficult to collect. Analysis of growth factors expression at the mRNA level requires, however, a much lower number of chondrocytes than analysis of their presence as proteins in calcified cartilage. Human chondrocytes, for example, from the costochondral junctions of young transplant donors, could be accessible with maintaining ethical standards according to the Academy of Medical Royal Colleges, 2015; Recommendation 9: "When parents would like to donate their child's organs for transplantation, but this is not clinically possible, clinicians should attempt wherever possible to accept such organs for research, if this is an acceptable alternative to the parents" [42].

The aim of our study was to check whether the expression of genes encoding growth factors by growth plate chondrocytes may be related to the amount of the respective proteins in calcified cartilage. For the verification of this supposition, we evaluated the expression of growth factors at the mRNA level in growth plate chondrocytes in an animal model and tried to deduce which of them are essential for the stimulation of osteoprogenitor cells and, presumably, are deposited in calcified cartilage. Because in the previous work [27] we used calf cartilage, the best way to test this hypothesis would be to use calf chondrocytes, unfortunately they could be collected at the earliest $24 \mathrm{~h}$ after death of the animal. Therefore, we used rat chondrocytes from the proliferative and hypertrophic zone of epiphyseal cartilage of costochondral junction, to evaluate mRNA level of selected growth factors: BMPs 1-7, VEGF-A, bFGF, GDF-5, NELL-1, TGF- $\beta 1$, MANF, CTGF, OSTF- 1 and IGF-1.

\section{Materials and methods}

Animals. Donors of chondrocytes were 6-week-old inbred Lewis male rats. Cartilages were taken from two rats for one experiment (number of experiments was $5, \mathrm{n}=5$ ). The study was approved by the Animal Ethics Committee of the Medical University of Warsaw, Poland (no 049/2016).

Preparation of cartilage. Ribs were dissected from costochondral junctions and cleared from the adhering tissues. The metaphysis was identified under dissecting microscope, separated from cartilage and about $1 \mathrm{~mm}$ in length of cartilage containing hypertrophic and proliferative zones was taken either for chondrocyte isolation or histological observations.

Isolation of chondrocytes. Cartilages taken from two rats for one experiment were left in $0.125 \%$ collagenase and $0.025 \%$ DNase solution dissolved in RPMI 1640 medium (Merck KGaA, Darmstadt, Germany) at $37^{\circ} \mathrm{C}$ for 18 hours. During the last hour of exposition, the suspension of partially digested cartilage fragments was stirred on the magnetic stirrer to facilitate dispersion into single cells. Non-digested (calcified) fragments were separated with $20 \mu \mathrm{m}$ mesh filter (Merck). Isolated chondrocytes were counted in the Bürger's chamber. About $2 \times 10^{6}$ chondrocytes was obtained from two rats. Chondrocytes were used for isolation of total RNA.

Total RNA isolation. RNA was isolated with NucleoSpin ${ }^{\circledR} \mathrm{R}$ NA II kit (Macherey-Nagel, Duren, Germany), according to manufacturer's protocol. The quantity and quality of the isolated total RNA was evaluated spectrophotometrically using ND-2000-Spectrophotometer NanoDrop 2000 with software for analysis of nucleic acids (Thermo Fisher Scientific, Wilmington, DE, USA).

Reverse transcription. Reverse transcription was performed using the High Capacity cDNA Reverse Transcription kit (Applied Biosystems, Warrington, UK), according to the manufacturer's protocol in Eppendorf Mastercycler gradient $\left(10 \mathrm{~min}\right.$ at $25^{\circ} \mathrm{C}, 120 \mathrm{~min}$ at $37^{\circ} \mathrm{C}$ and $5 \mathrm{sec}$. at $85^{\circ} \mathrm{C}$ ). Briefly, $2 \mu \mathrm{l}$ of $10 \times$ RT buffer, $0.8 \mu$ l of $25 \mathrm{x}$ dNTP Mix, $2 \mu$ l of $10 \times$ Random Primers, $1 \mu$ l of Multiscribe Reverse Transcriptase, $4.2 \mu \mathrm{l}$ of nuclease-free water and $10 \mu \mathrm{l}$ of mRNA $(0.5 \mu \mathrm{g})$ per one reaction. cDNA samples were stored at $-20^{\circ} \mathrm{C}$.

Real-time PCR. Real-time PCR was performed in the ABIPRISM 7500 (Applied Biosystems) using 96-well optical plates. Each sample was run in triplicate and was supplied with an endogenous control (Rat GAPDH endogenous control Rn01775763_g1). For gene expression analysis, proper TaqMan expression assays was used: Rn00686607_ m1 for OSTF-1, Rn00563954_m1 for type II collagen, Rn01466014_m1 for BMP-1, Rn00567818_m1 for BMP-2, Rn00567346_m1 for BMP-3, Rn00432087_m1 for BMP-4, Rn01447676_m1 for BMP-5, Rn00432095_m1 for BMP-6, Rn01528889_m1 for BMP-7, Rn01511602_m1 for VEGF A, Rn00572010_m1 for TGF- $\beta 1$, Rn01445633_m1 for MANF, Rn00710306_m1 for IGF1, Rn00433564_m1 for GDF-5, Rn01537279_g1 for CTGF, Rn00570809_m1 for bFGF, and 


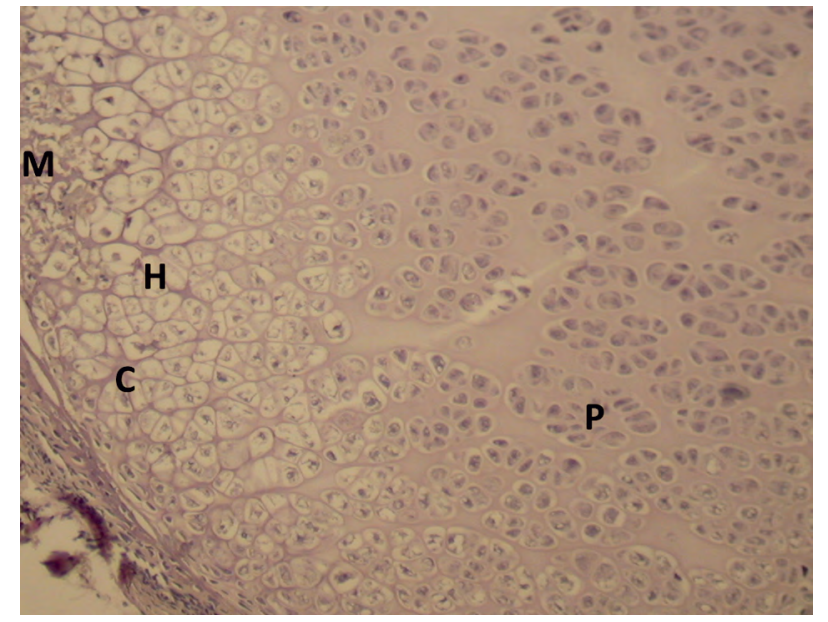

Figure 1. Fragment of rat rib costochondral junction. $\mathrm{P}$ - zone of proliferative chondrocytes; $\mathrm{H}$ - zone of hypertrophic chondrocytes; $\mathrm{C}$ - zone of provisional calcification; $\mathrm{M}$ - metaphysis; $\mathrm{PC}$ - perichondrium. In the section, chondrocytes from the proliferative zone are predominant; hypertrophic chondrocytes are considerably shrunken due to fixation and embedding. H\&E staining. Total magnification $100 \times$.

Rn00675924_m1 for NELL-1. All probes were stained with FAM (Applied Biosystems). Reactions were run in $25 \mu \mathrm{l}$ with TaqMan Universal Master Mix, appropriate primer set, MGB probe and $50 \mathrm{ng}$ of cDNA template. Universal thermal conditions, $10 \mathrm{~min}$ at $95^{\circ} \mathrm{C}, 40$ cycles of $15 \mathrm{sec}$ at $95^{\circ} \mathrm{C}$ and $1 \mathrm{~min}$ at $60^{\circ} \mathrm{C}$, were used. Data analysis was done with sequence detection software version 1.2 (Applied Biosystems). Relative expression was calculated against the reference gene, GAPDH. This reference gene is acceptable in studies on gene expression in normal chondrocytes and bone cells [43-45]. Analysis was conducted as a $\Delta \mathrm{CT}$ values using sequence detection software ver. 1.2 (Applied Biosystems).

Histology. Ribs were fixed in $10 \%$ buffered formalin, dehydrated, embedded in paraffin, sectioned at $6 \mu \mathrm{m}$ thick slices and stained with haematoxylin and eosin.

\section{Results}

\section{Morphology of the epiphyseal cartilage sections}

Fragment of rat rib costochondral junction is shown at Figure 1. It is a tissue section from the fragment of cartilage used for enzymatic digestion and further isolation of cells. Section demonstrates zone of proliferative chondrocytes $(\mathrm{P})$, zone of hypertrophic chondrocytes $(\mathrm{H})$, zone of provisional calcification (C), metaphysis (M) and perichondrium (PC). Predominate chondrocytes are present in the proliferative zone, hypertrophic chondrocytes are considerably shrunken due to fixation and embedding. Fragments of cartilage dissected for chondrocyte isolation con- tained mainly cells from the proliferative zone since the zone of hypertrophic chondrocytes was narrow and cells from provisional calcification were not isolated because calcium deposits prevented access of collagenase.

\section{The expression of the studied growth factors at the mRNA level}

The relative expression of the genes encoding the studied growth factors in chondrocytes from the digested epiphyseal cartilage was calculated against the reference gene, GAPDH, and presented as the $\triangle \mathrm{CT}$ values at Figure 2. The obtained results indicate that mRNA for all studied factors were expressed but the level of the expression considerably differed. The highest levels of mRNA were detected for CTGF, MANF, VEGF-A and TGF- $\beta 1$. The expression was also quite high for BMP-1, BMP-2, BMP-5, BMP-6, BMP-7, IGF-1, GDF-5, and OSTF-1. Very low level of mRNA was detected for BMP-3, BMP-4, and NELL-1 (Fig. 2).

\section{Discussion}

As we have reported previously [27], growth factors present in calcified and small amount of adhering non-calcified matrix of calf rib costochondral junction could form a depot released by septoclasts and osteoclasts and are involved in early stages of bone formation. From the 16 growth factors studied in calf epiphyseal cartilage only nine (BMP-2, BMP-3, BMP-4, BMP-7, GDF-5, NELL-1, TGF- $\beta 1$, bFGF and VEGF) were identified by ELISA [27], however, all of them were expressed at the mRNA level by rat epiphyseal chondrocytes. The highest expression showed CTGF, cytokine which participates in the matrix turnover by binding to ECM proteins $[46,47]$ and MANF. The role of MANF in skeletal tissue homeostasis is currently unknown but in transgenic Manf null mice the growth of long bones was reduced [48]. Both factors do not appear to have prominent function in the stimulation of bone growth, thus their absence in calf calcified matrix is not surprising [27]. OSTF1 was identified as a factor involved in the indirect activation of osteoclasts [49] but its role, if any, in early stages of osteogenesis remains unknown.

BMP-1, BMP-5, BMP-6 and IGF-1, also not detected by ELISA in bovine calcified cartilage [27], are known to take part in various stages of bone formation. BMP-1 participates in the formation of mammalian extracellular matrix (ECM), and in the formation of bone through activation of TGF- $\beta[50$, 51]. BMP-5 is expressed in chondrocytes of proliferating zone and its expression increased sharply with hypertrophic differentiation in tibial growth plates 


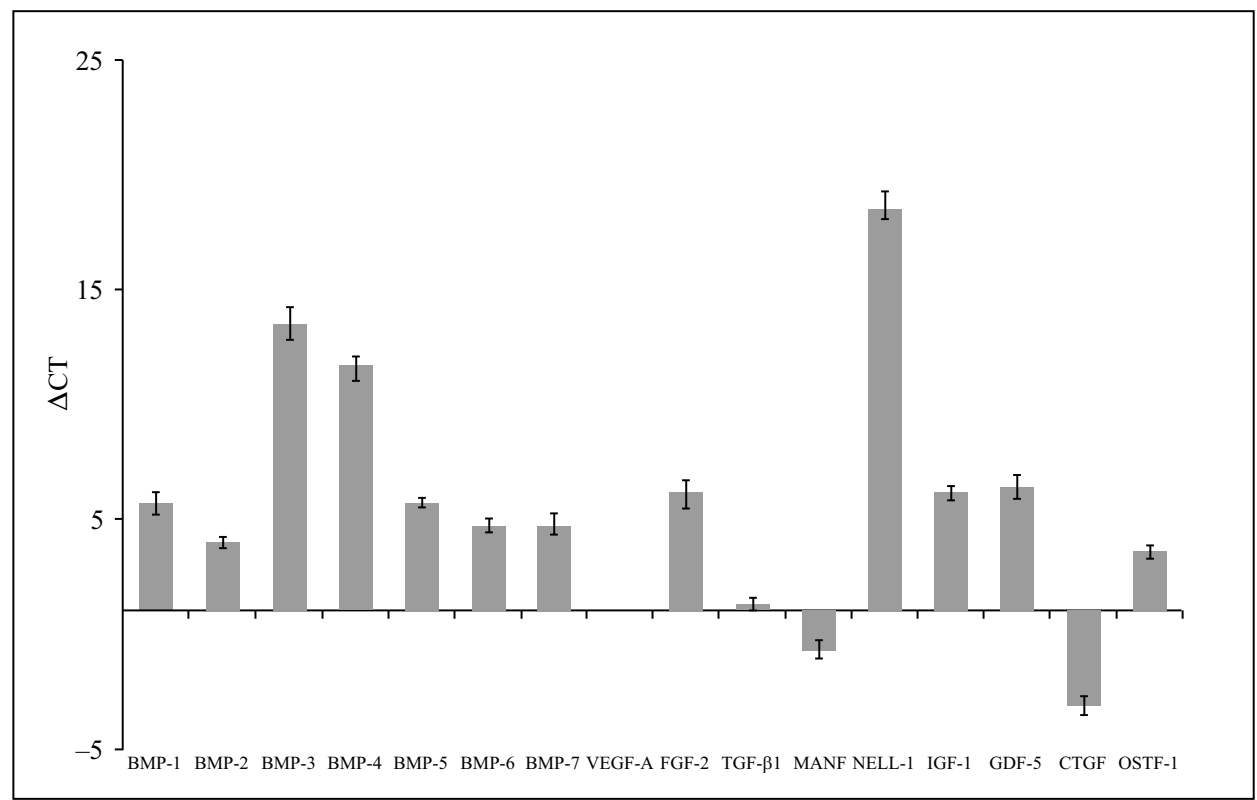

Figure 2. Average $\triangle \mathrm{CT}$ values $( \pm \mathrm{SE}$ ) as determined by real-time PCR by subtracting the average GAPDH CT value from the average growth $\mathrm{CT}$ values $(\mathrm{n}=5)$ calculated using sequence detection software ver. 1.2 (Applied Biosystems).

from normal rats [52]. BMP-6 is highly expressed during proliferation and differentiation of chondrocytes from shanks of 15-day-old chicken embryos. When its expression decreases, the proliferation and differentiation of chondrocytes are blocked [53]. BMP-5 and BMP-6 induce the formation of cartilage and bone in the rat subcutaneous transplant model, but the former requires higher doses for similar osteoinduction [31]. IGF-1 regulates bone length of the skeleton acting on chondrocytes of the proliferative and hypertrophic zones of the growth plate $[8,54,55]$.

From growth factors found in bovine epiphyseal calcified cartilage [27] and expressed, as shown in this study at the mRNA level in rat chondrocytes, BMP-2 not only stimulates bone formation [56] but significantly enhances osteoclastogenesis [57]. Moreover, BMP-2 also regulates chondrogenic and osteogenic differentiation of mesenchymal stem cells in vitro and in vivo [58]. BMP-3 is an inhibitor of osteogenesis in vitro and of bone formation in vivo and may antagonize BMP-2 signalling [59, 60]. BMP-4 acts synergistically with VEGF to increase recruitment of mesenchymal stem cells and to augment cartilage formation in the early stages of endochondral bone formation [61]. BMP-4 promotes cartilage growth, matrix deposition and chondrocyte proliferation as well as alkaline phosphatase and collagen type X expression in hypertrophic chondrocytes [62] but was less efficient than BMP-2 in promoting bone formation in a calvarial defect model [63]. Both BMP-2 and BMP-7 (also known as osteogenic protein-1) seem to induce bone formation at the same level in rat subcutaneous transplant model [56].
GDF-5 (BMP 14) is predominantly found at the stage of precartilaginous mesenchymal condensation and throughout the cartilaginous cores of the developing calf long bones [64]. In transgenic mice model it is responsible for mesenchymal cell recruitment and chondrocyte differentiation [65] as well as for proper skeletal patterning and joint development in the vertebrate limb $[66,67]$.

NELL-1 is not a member of TGF- $\beta$ superfamily, but it is highly specific to the osteochondral lineage and can promote orthotopic bone regeneration [68-70]. The chondrocyte-specific NELL-1 inactivation in knockout mice significantly impedes appendicular skeletogenesis [71]. The low level of NELL-1 gene expression in rat epiphyseal chondrocytes contrasts with data from bovine calcified cartilage [27] in which considerable amount of NELL-1 protein is deposited. TGF- $\beta 1$, highly expressed in rat chondrocytes, is involved in formation, maturation, and mineralization of cartilage as well as skeletal development $[72,73]$.

FGF-2 was detected immunohistochemically in the cytoplasm of proliferating chondrocytes and upper hypertrophic chondrocytes in human vertebrae [7] and mouse tibial growth plate [74]. It stimulated endosteal and endochondral bone formation and depressed periosteal bone formation in growing rats [75].

VEGF is expressed by hypertrophic chondrocytes [21, 76, 77]. Members of the VEGF family are essential coordinators of chondrocyte death, chondroclast function, extracellular matrix remodelling, angiogenesis and endochondral ossification cooperating with other growth factors in differentiation 
of osteoblasts and osteoclasts [3, 78, 79]. The high expression of VEGF by rat epiphyseal chondrocytes well corresponds with the data presented by above quoted authors.

It is evident from the data presented above that formation, maturation and differentiation of endochondral cartilage is under control of numerous growth factors. Moreover, some growth factors necessary for stimulation of endochondral ossification are stored in calcified and also in attached to it non-calcified cartilage. They are transported in matrix vesicles together with alkaline phosphatase and substrates for calcium phosphate deposition into cartilage matrix [11,14]. Thus, the assumption that the amount of growth factors deposited in calcified cartilage is related to their expression in chondrocytes from proliferative and hypertrophic zones seems justified.

Comparison of growth factors expression by rat and human growth plate chondrocytes is difficult due to the scarcity of data of the latter. Anderson et al. [13] in the histochemical study found that proliferating chondrocytes from human growth plate express BMP-1, BMP-2, BMP-5, BMP-6 at moderate (marked ++ ) and BMP-3, BMP-7 at the minimal level (marked + or \pm ). In hypertrophic chondrocytes all studied BMPs were expressed at the moderate or maximal $(+++)$ level. Thus, evaluation of the histochemical data from growth plate cartilage does not allow predicting which of the BMPs dominate in the initial stages of bone formation in metaphysis. Expression of GDF-5 and NELL-1 in human growth plate, as far as we could establish, was never studied.

Comparison of the results of Iwan et al. [27] and those in this work indicates a distinct species difference between calf and rat. In calf epiphyseal cartilage depot of bone growth factors consisted mainly of NELL-1, BMP-7 and GDF-5. Taking into consideration osteogenic activity of some growth factors and based on rat growth factors mRNA level, we can suppose that in the rat depot of these growth factors, presumably predominate BMP-2 with participation of BMP-6, BMP-7 and possible TGF- $\beta 1$.

We have also compared results of our Real-time PCR study with results of immunochemical observations of other authors. Nillson et al. [18] microdissected chondrocytes from resting zone, proliferative zone, proliferative-hypertrophic transition zone, and hypertrophic zone of proximal tibial epiphyses of 7-day-old rats and used them to isolate RNA. Expression of BMP-2, BMP-3, BMP-4, BMP-6 and BMP-7 was studied; mRNAs of BMP-2; BMP-6 and BMP-7 predominated in all zones. The high level of BMP-2; BMP-6 and BMP-7 mRNAs was also evident in our work [27], in which chondrocytes from 6-week-old rats were used. Thus, the sophisticated microdissection study and our tissue culture experiments gave similar results suggesting that the expression of BMPs in chondrocytes is not age-dependent, at least within 7-day - 6-week period. Mailhot et al. [52] studied expression of BMP-5 in tibial growth plates from 2- and 4-week-old rats by immunohistochemistry and found that its expression is upregulated in hypertrophic zone chondrocytes when compared with those in the proliferating zone. The expression of BMP -5 was also observed in our study at the mRNA level.

Horner et al. [20] immunolocalised VEGF in human neonatal growth plates. Immunoreactivity was absent in chondrocytes from the resting zone and only weakly expressed by occasional chondrocytes in the proliferating region. In the hypertrophic zone the number of chondrocytes stained and the intensity of staining for VEGF increased with chondrocytes' hypertrophy, maximum expression of VEGF being observed in chondrocytes in the lower hypertrophic and mineralised regions of the cartilage. The authors concluded that VEGF produced by hypertrophic chondrocytes may play a key role in the regulation of vascular invasion of the growth plate. Marked expression of VEGF was also observed in the rat growth plate chondrocytes in our study.

In another paper Horner et al. [80] detected by immunolocalisation TGF- $\beta 1$ in human epiphyseal cartilage. Its expression was restricted to the proliferative and upper hypertrophic zones, i.e., approximately in the same areas in which we detected TGF- $\beta 1$ in rat cartilage. Wezeman and Bollnow [74] in mouse tibial growth plate detected by immunostaining bFGF in the extracellular matrix immediately adjacent to the chondrocytes of the proliferating and upper hypertrophic zones. We have detected expression of bFGF in chondrocytes from the same zones of rat growth plates. Evidently, mouse chondrocytes secreted most of the product and the amount left in cells was too low for immunodetection.

Our study describes expression of growth factors in chondrocytes from rat growth plate at the mRNA level. The number of chondrocytes used in the present study is insufficient for determination of the quantity of growth factors produced by the expressed genes. The results of the study encourage, however, their continuation with mass isolation of chondrocytes from large number of rats followed by ELISA tests.

We hope that the similar studies with human material (for example using costochondral junctions of young organ donors) will allow to determine which growth factors predominate in endochondral ossification in humans so that the composition of these factors will be useful in the treatment of bone disorders. 


\section{Acknowledgements}

Not applicable.

\section{Funding}

This research was supported by the National Science Centre, Poland (grant no. 2016/21/B/NZ1/00289).

\section{Availability of data and materials}

The datasets used and/or analysed during the present study are available from the corresponding author on reasonable request.

\section{Authors' contributions}

SM designed the study. AH and AI performed the experiments. $\mathrm{AH}, \mathrm{SM}$ and $\mathrm{AI}$ analysed the data. $\mathrm{AH}$, $\mathrm{SM}$ and AI wrote the manuscript. All authors have read and approved the final manuscript. AI, SM and $\mathrm{AH}$ confirmed the authenticity of all the raw data.

\section{Ethics approval and consent to participate}

The study was approved by the Animal Ethical Committee of the Medical University of Warsaw.

\section{Conflict of interests}

All authors declare no conflicts of interest in this work.

\section{References}

1. Adams SL, Cohen AJ, Lassová L. Integration of signaling pathways regulating chondrocyte differentiation during endochondral bone formation. J Cell Physiol. 2007; 213(3): 635-641, doi: 10.1002/jcp.21262, indexed in Pubmed: 17886256.

2. Amizuka N, Hasegawa T, Oda K, et al. Histology of epiphyseal cartilage calcification and endochondral ossification. Front Biosci (Elite Ed). 2012; 4: 2085-2100, doi: 10.2741/526, indexed in Pubmed: 22202021.

3. Patil AS, Sable RB, Kothari RM. Occurrence, biochemical profile of vascular endothelial growth factor (VEGF) isoforms and their functions in endochondral ossification. J Cell Physiol. 2012; 227(4): 1298-1308, doi: 10.1002/jcp.22846, indexed in Pubmed: 21604271.

4. Burdan F, Szumiło J, Korobowicz A, et al. Morphology and physiology of the epiphyseal growth plate. Folia Histochem Cytobiol. 2009; 47(1): 5-16, doi: 10.2478/v10042-009-0007-1, indexed in Pubmed: 19419931.

5. Brochhausen C, Lehmann M, Halstenberg S, et al. Signalling molecules and growth factors for tissue engineering of cartilage-what can we learn from the growth plate? J Tissue Eng Regen Med. 2009; 3(6): 416-429, doi: 10.1002/term.192, indexed in Pubmed: 19575393.

6. Mackie EJ, Tatarczuch L, Mirams M. The skeleton: a multi-functional complex organ: the growth plate chondrocyte and endochondral ossification. J Endocrinol. 2011; 211(2): 109-121, doi: 10.1530/JOE-11-0048, indexed in Pubmed: 21642379.

7. Marino R. Growth plate biology: new insights. Curr Opin Endocrinol Diabetes Obes. 2011; 18(1): 9-13, doi: 10.1097/ MED.0b013e3283423df9, indexed in Pubmed: 21157322.

8. Lui JC, Nilsson O, Baron J. Recent research on the growth plate: Recent insights into the regulation of the growth plate. J Mol Endocrinol. 2014; 53(1): T1-T9, doi: 10.1530/JME-140022, indexed in Pubmed: 24740736.
9. Bonucci E. Fine structure of early cartilage calcification. J Ultrastruct Res. 1967; 20(1): 33-50, doi: 10.1016/s00225320(67)80034-0, indexed in Pubmed: 4195919.

10. Ali SY, Sajdera SW, Anderson HC. Isolation and characterization of calcifying matrix vesicles from epiphyseal cartilage. Proc Natl Acad Sci U S A. 1970; 67(3): 1513-1520, doi: 10.1073/pnas.67.3.1513, indexed in Pubmed: 5274475.

11. Anderson H. Vesicles associated with calcification in the matrix of epiphyseal cartilage. J Cell Biol. 1969; 41(1): 59-72, doi: 10.1083/jcb.41.1.59, indexed in Pubmed: 5775794.

12. Jaroszewicz J, Bazarnik P, Osiecka-Iwan A, et al. From matrix vesicles to miniature rocks: evolution of calcium deposits in calf costochondral junctions. Cartilage. 2020 [Epub ahead of print]: 1947603520941225, doi: 10.1177/1947603520941225, indexed in Pubmed: 32672056.

13. Anderson HC, Hodges PT, Aguilera XM, et al. Bone morphogenetic protein (BMP) localization in developing human and rat growth plate, metaphysis, epiphysis, and articular cartilage. J Histochem Cytochem. 2000; 48(11): 1493-1502, doi: 10.1177/002215540004801106, indexed in Pubmed: 11036092 .

14. Nahar NN, Missana LR, Garimella R, et al. Matrix vesicles are carriers of bone morphogenetic proteins (BMPs), vascular endothelial growth factor (VEGF), and noncollagenous matrix proteins. J Bone Miner Metab. 2008; 26(5): 514-519, doi: 10.1007/s00774-008-0859-z, indexed in $\mathrm{Pu}-$ bmed: 18758911.

15. Enomoto-Iwamoto M, Iwamoto M, Mukudai Y, et al. Bone morphogenetic protein signaling is required for maintenance of differentiated phenotype, control of proliferation, and hypertrophy in chondrocytes. J Cell Biol. 1998; 140(2): 409-418, doi: 10.1083/jcb.140.2.409, indexed in Pubmed: 9442116.

16. Tsumaki N, Yoshikawa $\mathrm{H}$. The role of bone morphogenetic proteins in endochondral bone formation. Cytokine \& Growth Factor Reviews. 2005; 16(3): 279-285, doi: 10.1016/j.cytogfr.2005.04.001, indexed in Pubmed: 15869898.

17. Salazar VS, Gamer LW, Rosen V. BMP signalling in skeletal development, disease and repair. Nat Rev Endocrinol. 2016; 12(4): 203-221, doi: 10.1038/nrendo.2016.12, indexed in Pubmed: 26893264.

18. Nilsson O, Parker EA, Hegde A, et al. Gradients in bone morphogenetic protein-related gene expression across the growth plate. J Endocrinol. 2007; 193(1): 75-84, doi: 10.1677/ joe.1.07099, indexed in Pubmed: 17400805 .

19. Snelling SJB, Hulley PA, Loughlin J. BMP5 activates multiple signaling pathways and promotes chondrogenic differentiation in the ATDC5 growth plate model. Growth Factors. 2010; 28(4): 268-279, doi: 10.3109/08977191003752296, indexed in Pubmed: 20402566.

20. Horner A, Bishop NJ, Bord S, et al. Immunolocalisation of vascular endothelial growth factor (VEGF) in human neonatal growth plate cartilage. J Anat. 1999; 194 ( Pt 4): 519-524, doi: 10.1046/j.1469-7580.1999.19440519.x, indexed in Pubmed: 10445820 .

21. Carlevaro MF, Cermelli S, Cancedda R, et al. Vascular endothelial growth factor (VEGF) in cartilage neovascularization and chondrocyte differentiation: auto-paracrine role during endochondral bone formation. J Cell Sci. 2000; 113 ( Pt 1): 59-69, doi: org/10.1242/jcs.113.1.59, indexed in $\mathrm{Pu}-$ bmed: 10591625 .

22. Engsig MT, Chen QJ, Vu TH, et al. Matrix metalloproteinase 9 and vascular endothelial growth factor are essential for osteoclast recruitment into developing long bones. J Cell Biol. 2000; 151(4): 879-889, doi: 10.1083/jcb.151.4.879, indexed in Pubmed: 11076971. 
23. Ortega N, Wang Ke, Ferrara N, et al. Complementary interplay between matrix metalloproteinase-9, vascular endothelial growth factor and osteoclast function drives endochondral bone formation. Dis Model Mech. 2010; 3(3-4): 224-235, doi: 10.1242/dmm.004226, indexed in Pubmed: 20142327.

24. Yang YQ, Tan YY, Wong R, et al. The role of vascular endothelial growth factor in ossification. Int J Oral Sci. 2012; 4(2): 64-68, doi: 10.1038/ijos.2012.33, indexed in Pubmed: 22722639.

25. Kerkhofs J, Roberts SJ, Luyten FP, et al. Relating the chondrocyte gene network to growth plate morphology: from genes to phenotype. PLoS One. 2012; 7(4): e34729, doi: 10.1371/ journal.pone.0034729, indexed in Pubmed: 22558096.

26. Li Bo, Wang H, Qiu G, et al. Synergistic Effects of Vascular Endothelial Growth Factor on Bone Morphogenetic Proteins Induced Bone Formation In Vivo: Influencing Factors and Future Research Directions. Biomed Res Int. 2016; 2016: 2869572, doi: 10.1155/2016/2869572, indexed in Pubmed: 28070506.

27. Iwan A, Moskalewski S, Hyc A. Growth factor profile in calcified cartilage from the metaphysis of a calf costochondral junction, the site of initial bone formation. Biomed Rep. 2021; 14(6): 54, doi: 10.3892/br.2021.1430, indexed in Pubmed: 33884197.

28. Brighton C, Sugioka Y, Hunt R. Cytoplasmic structures of epiphyseal plate chondrocytes. J Bone Joint Surg. 1973; 55(4): 771-784, doi: 10.2106/00004623-197355040-00012, indexed in Pubmed: 4283751.

29. Byard RW, Foster BK, Byers S. Immunohistochemical characterisation of the costochondral junction in SIDS. J Clin Pathol. 1993; 46(2): 108-112, doi: 10.1136/jcp.46.2.108, indexed in Pubmed: 8459029.

30. Clark CC, Tolin BS, Brighton CT. The effect of oxygen tension on proteoglycan synthesis and aggregation in mammalian growth plate chondrocytes. J Orthop Res. 1991; 9(4): 477-484, doi: 10.1002/jor.1100090403, indexed in Pubmed: 2045974.

31. Wozney J. Overview of bone morphogenetic proteins. Spine. 2002; 27(Suppl.): S2-S8, doi: 10.1097/00007632-20020815100002, indexed in Pubmed: 12205411.

32. Termaat MF, Den Boer FC, Bakker FC, et al. Bone morphogenetic proteins. Development and clinical efficacy in the treatment of fractures and bone defects. J Bone Joint Surg Am. 2005; 87(6): 1367-1378, doi: 10.2106/JBJS.D.02585, indexed in Pubmed: 15930551.

33. Vukicevic S, Oppermann H, Verbanac D, et al. The clinical use of bone morphogenetic proteins revisited: a novel biocompatible carrier device OSTEOGROW for bone healing. Int Orthop. 2014; 38(3): 635-647, doi: 10.1007/s00264-0132201-1, indexed in Pubmed: 24352822.

34. James AW, LaChaud G, Shen J, et al. A review of the clinical side effects of bone morphogenetic protein-2. Tissue Eng Part B Rev. 2016; 22(4): 284-297, doi: 10.1089/ten.TEB.2015.0357, indexed in Pubmed: 26857241.

35. Epstein NE. Basic science and spine literature document bone morphogenetic protein increases cancer risk. Surg Neurol Int. 2014; 5(Suppl 15): S552-S560, doi: 10.4103/2152-7806.148039, indexed in Pubmed: 25593776.

36. Seeherman H, Wozney JM. Delivery of bone morphogenetic proteins for orthopedic tissue regeneration. Cytokine Growth Factor Rev. 2005; 16(3): 329-345, doi: 10.1016/j.cytogfr.2005.05.001, indexed in Pubmed: 15936978.

37. Park SY, Kim KH, Kim S, et al. BMP-2 Gene Delivery-Based Bone Regeneration in Dentistry. Pharmaceutics. 2019; 11(8), doi: 10.3390/pharmaceutics11080393, indexed in Pubmed: 31387267.
38. Loozen LD, Kruyt MC, Kragten AHM, et al. BMP-2 gene delivery in cell-loaded and cell-free constructs for bone regeneration. PLoS One. 2019; 14(7): e0220028, doi: 10.1371/ journal.pone.0220028, indexed in Pubmed: 31365542.

39. Mumcuoglu D, Fahmy-Garcia S, Ridwan Y, et al. Injectable BMP-2 delivery system based on collagen-derived microspheres and alginate induced bone formation in a time- and dose-dependent manner. Eur Cell Mater. 2018; 35: 242-254, doi: 10.22203/eCM.v035a17, indexed in Pubmed: 29697853.

40. Maisani M, Sindhu KR, Fenelon M, et al. Prolonged delivery of BMP-2 by a non-polymer hydrogel for bone defect regeneration. Drug Deliv Transl Res. 2018; 8(1): 178-190, doi: 10.1007/s13346-017-0451-y, indexed in Pubmed: 29192408.

41. Marsell R, Einhorn TA. The biology of fracture healing. Injury. 2011; 42(6): 551-555, doi: 10.1016/j.injury.2011.03.031, indexed in Pubmed: 21489527.

42. Academy of Medical Royal Colleges. Ethical issues in paediatric organ donation. UK Donation Ethics Committee (UKDEC) 2015:4. URL: https://www.aomrc.org.uk/wp-content/uploads/2016/04/Paediatric_organ_donation_position_0615-2.pdf.

43. He $\overline{\mathrm{T}}$, Huang Y, Chak JC, et al. Recommendations for improving accuracy of gene expression data in bone and cartilage tissue engineering. Sci Rep. 2018; 8(1): 14874, doi: 10.1038/ s41598-018-33242-z, indexed in Pubmed: 30291289.

44. Lopa S, Ceriani C, Cecchinato R, et al. Stability of housekeeping genes in human intervertebral disc, endplate and articular cartilage cells in multiple conditions for reliable transcriptional analysis. Eur Cell Mater. 2016; 31: 395-406, doi: 10.22203/ecm.v031a25, indexed in Pubmed: 27232666.

45. Han H, Liu L, Chen M, et al. The optimal compound reference genes for qRT-PCR analysis in the developing rat long bones under physiological conditions and prenatal dexamethasone exposure model. Reprod Toxicol. 2020; 98: 242-251, doi: 10.1016/j.reprotox.2020.10.008, indexed in Pubmed: 33086097.

46. Arnott JA, Lambi AG, Mundy C, et al. The role of connective tissue growth factor $(\mathrm{CTGF} / \mathrm{CCN} 2)$ in skeletogenesis. Crit Rev Eukaryot Gene Expr. 2011; 21(1): 43-69, doi: 10.1615/critreveukargeneexpr.v21.i1.40, indexed in Pubmed: 21967332.

47. Ramazani Y, Knops N, Elmonem MA, et al. Connective tissue growth factor (CTGF) from basics to clinics. Matrix Biol. 2018; 68-69: 44-66, doi: 10.1016/j.matbio.2018.03.007, indexed in Pubmed: 29574063

48. Bell PA, Dennis EP, Hartley CL, et al. Mesencephalic astrocyte-derived neurotropic factor is an important factor in chondrocyte ER homeostasis. Cell Stress Chaperones. 2019; 24(1): 159-173, doi: 10.1007/s12192-018-0953-7, indexed in Pubmed: 30543055.

49. Reddy S, Devlin R, Menaa C, et al. Isolation and characterization of a cDNA clone encoding a novel peptide (OSF) that enhances osteoclast formation and bone resorption. J Cell Physiol. 1998; 177(4): 636-645, doi: 10.1002/(SICI)10974652(199812)177:4<636::AID-JCP14>3.0.CO;2-H, indexed in Pubmed: 10092216.

50. Steiglitz BM, Ayala M, Narayanan K, et al. Bone morphogenetic protein-1/Tolloid-like proteinases process dentin matrix protein-1. J Biol Chem. 2004; 279(2): 980-986, doi: 10.1074/ jbc.M310179200, indexed in Pubmed: 14578349.

51. Vadon-Le Goff S, Hulmes DJS, Moali C. BMP-1/tolloidlike proteinases synchronize matrix assembly with growth factor activation to promote morphogenesis and tissue remodeling. Matrix Biol. 2015; 44-46: 14-23, doi: 10.1016/j. matbio.2015.02.006, indexed in Pubmed: 25701650.

52. Mailhot G, Yang M, Mason-Savas A, et al. BMP-5 expression increases during chondrocyte differentiation in vivo and in vit- 
ro and promotes proliferation and cartilage matrix synthesis in primary chondrocyte cultures. J Cell Physiol. 2008; 214(1): 56-64, doi: 10.1002/jcp.21164, indexed in Pubmed: 17541940.

53. Ye F, Xu H, Yin H, et al. The role of BMP6 in the proliferation and differentiation of chicken cartilage cells. PLoS One. 2019; 14(7): e0204384, doi: 10.1371/journal.pone.0204384, indexed in Pubmed: 31260450.

54. Yakar S, Werner H, Rosen CJ. Insulin-like growth factors: actions on the skeleton. J Mol Endocrinol. 2018; 61(1): T115-T137, doi: 10.1530/JME-17-0298, indexed in Pubmed: 29626053

55. Racine HL, Serrat MA. The Actions of IGF-1 in the Growth Plate and Its Role in Postnatal Bone Elongation. Curr Osteoporos Rep. 2020; 18(3): 210-227, doi: 10.1007/s11914-02000570-x, indexed in Pubmed: 32415542.

56. Wozney JM, Rosen V. Bone morphogenetic protein and bone morphogenetic protein gene family in bone formation and repair. Clin Orthop Relat Res. 1998(346): 26-37, indexed in Pubmed: 9577407.

57. Wutzl A, Rauner M, Seemann R, et al. Bone morphogenetic proteins 2, 5, and 6 in combination stimulate osteoblasts but not osteoclasts in vitro. J Orthop Res. 2010; 28(11): 14311439, doi: 10.1002/jor.21144, indexed in Pubmed: 20872578.

58. Zhou N, Li Qi, Lin X, et al. BMP2 induces chondrogenic differentiation, osteogenic differentiation and endochondral ossification in stem cells. Cell Tissue Res. 2016; 366(1): 101-111, doi: 10.1007/s00441-016-2403-0, indexed in Pubmed: 27083447

59. Bahamonde M, Lyons K. BMP3: To Be or Not To Be a BMP. J Bone Joint Surg Am-American Volume. 2001; 83: S1-56S1-62, doi: 10.2106/00004623-200100001-00008, indexed in Pubmed: 11263666.

60. Gamer LW, Cox K, Carlo JM, et al. Overexpression of BMP3 in the developing skeleton alters endochondral bone formation resulting in spontaneous rib fractures. Dev Dyn. 2009; 238(9): 2374-2381, doi: 10.1002/dvdy.22048, indexed in $\mathrm{Pu}-$ bmed: 19653325.

61. Peng H, Wright V, Usas A, et al. Synergistic enhancement of bone formation and healing by stem cell-expressed VEGF and bone morphogenetic protein-4. J Clin Invest. 2002; 110(6): 751-759, doi: 10.1172/JCI15153, indexed in Pubmed: 12235106.

62. Shum L, Wang X, Kane AA, et al. BMP4 promotes chondrocyte proliferation and hypertrophy in the endochondral cranial base. Int J Dev Biol 2003;47(6):423-431, indexed in Pubmed: 14598792.

63. Gao X, Usas A, Lu A, et al. BMP2 is superior to BMP4 for promoting human muscle-derived stem cell-mediated bone regeneration in a critical-sized calvarial defect model. Cell Transplant. 2013; 22(12): 2393-2408, doi 10.3727/096368912X658854, indexed in Pubmed: 23244588.

64. Chang SC, Hoang B, Thomas JT, et al. Cartilage-derived morphogenetic proteins. New members of the transforming growth factor-beta superfamily predominantly expressed in long bones during human embryonic development. J Biol Chem. 1994; 269(45): 28227-28234, indexed in Pubmed: 7961761.

65. Tsumaki N, Tanaka K, Arikawa-Hirasawa E, et al. Role of CDMP-1 in skeletal morphogenesis: promotion of mesenchymal cell recruitment and chondrocyte differentiation. J Cell Biol. 1999; 144(1): 161-173, doi: 10.1083/jcb.144.1.161, indexed in Pubmed: 9885252.

66. Storm EE, Huynh TV, Copeland NG, et al. Limb alterations in brachypodism mice due to mutations in a new member of the TGF beta-superfamily. Nature. 1994; 368(6472): 639-643, doi: 10.1038/368639a0, indexed in Pubmed: 8145850.

67. Polinkovsky A, Robin NH, Thomas JT, et al. Mutations in CDMP1 cause autosomal dominant brachydactyly type C. Nat Genet. 1997; 17(1): 18-19, doi: 10.1038/ng0997-18, indexed in Pubmed: 9288091

68. Zhang X, Zara J, Siu RK, et al. The role of NELL-1, a growth factor associated with craniosynostosis, in promoting bone regeneration. J Dent Res. 2010; 89(9): 865-878, doi: 10.1177/0022034510376401, indexed in Pubmed: 20647499.

69. Tanjaya J, Zhang Y, Lee S, et al. Efficacy of Intraperitoneal Administration of PEGylated NELL-1 for Bone Formation. Biores Open Access. 2016; 5(1): 159-170, doi: 10.1089/biores.2016.0018, indexed in Pubmed: 27354930.

70. James AW, Shen J, Tsuei R, et al. NELL-1 induces Sca-1+ mesenchymal progenitor cell expansion in models of bone maintenance and repair. JCI Insight. 2017; 2(12), doi: 10.1172/ jci.insight.92573, indexed in Pubmed: 28614787.

71. Qi H, Kim JK, Ha P, et al. Inactivation of nell-1 in chondrocytes significantly impedes appendicular skeletogenesis. J Bone Miner Res. 2019; 34(3): 533-546, doi: 10.1002/ jbmr.3615, indexed in Pubmed: 30352124.

72. Chen G, Deng C, Li YP. TGF- $\beta$ and BMP signaling in osteoblast differentiation and bone formation. Int J Biol Sci. 2012; 8(2): 272-288, doi: 10.7150/ijbs.2929, indexed in Pubmed: 22298955.

73. Wu M, Chen G, Li YP. TGF- $\beta$ and BMP signaling in osteoblast, skeletal development, and bone formation, homeostasis and disease. Bone Res. 2016; 4: 16009, doi: 10.1038/ boneres.2016.9, indexed in Pubmed: 27563484.

74. Wezeman FH, Bollnow MR. Immunohistochemical localization of fibroblast growth factor-2 in normal and brachymorphic mouse tibial growth plate and articular cartilage. Histochem J. 1997; 29(6): 505-514, doi: 10.1023/a:1026415707378, indexed in Pubmed: 9248858.

75. Nagai H, Tsukuda R, Mayahara H. Effects of basic fibroblast growth factor (bFGF) on bone formation in growing rats. Bone. 1995; 16(3): 367-373, doi: 10.1016/8756-3282(94)00049-2.

76. Kusafuka K, Hiraki Y, Shukunami C, et al. Cartilage-specific matrix protein, chondromodulin-I (ChM-I), is a strong angio-inhibitor in endochondral ossification of human neonatal vertebral tissues in vivo: relationship with angiogenic factors in the cartilage. Acta Histochem. 2002; 104(2): 167-175, doi: 10.1078/0065-1281-00642, indexed in Pubmed: 12086337.

77. Gerber HP, Vu TH, Ryan AM, et al. VEGF couples hypertrophic cartilage remodeling, ossification and angiogenesis during endochondral bone formation. Nat Med. 1999; 5(6): 623-628, doi: 10.1038/9467, indexed in Pubmed: 10371499.

78. Nagao M, Hamilton JL, Kc R, et al. Vascular endothelial growth factor in cartilage development and osteoarthritis. Sci Rep. 2017; 7(1): 13027, doi: 10.1038/s41598-017-13417-w, indexed in Pubmed: 29026147.

79. Vadalà G, Russo F, Musumeci M, et al. Targeting VEGF-A in cartilage repair and regeneration: state of the art and perspectives. J Biol Regul Homeost Agents 2018;32(6 suppl.): 217-224. , indexed in Pubmed: 30644305.

80. Horner A, Kemp P, Summers C, et al. Expression and distribution of transforming growth factor-beta isoforms and their signaling receptors in growing human bone. Bone. 1998; 23(2): 95-102, doi: 10.1016/s8756-3282(98)00080-5, indexed in Pubmed: 9701467.

Submitted: 2 June, 2021

Accepted after reviews: 13 July, 2021 Available as AoP: 30 July, 2021 